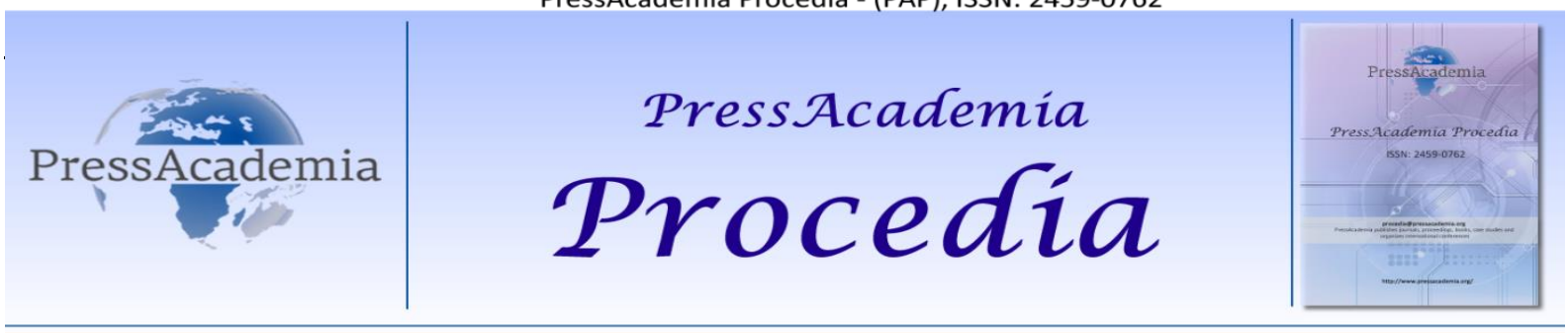

Global Business Research Congress (GBRC), May 24-25, 2017, Istanbul, Turkey.

\title{
ORGANIZATIONAL JUSTICE AS A DETERMINANT OF EFFECTIVE COMMITMENT AND SILENCE OF EMPLOYEES
}

\author{
DOI: 10.17261/Pressacademia.2017.435 \\ PAP-GBRC-V.3-2017(90)-p.825-840 \\ Huseyin Yesil', A. Begum Otken ${ }^{2}$, Hayriye Senem Gol Beser ${ }^{3}$ \\ ${ }^{1}$ Yeditepe University, Istanbul, Turkey, hyesil@gmail.com \\ ${ }^{2}$ Yeditepe University, Istanbul, Turkey, begum.otken@yeditepe.edu.tr \\ ${ }^{3}$ Yeditepe University, Istanbul, Turkey, senemgol@yeditepe.edu.tr
}

\section{To cite this document}

Yesil, H., A. B. Otken and H.S. G. Beser, (2017). Organizational justice as a determinant of effective commitment and silence of employees. PressAcademia Procedia (PAP), V.3, p.825-840.

Permemant link to this document: http://doi.org/10.17261/Pressacademia.2017.435

Copyright: Published by PressAcademia and limited licenced re-use rights only.

\begin{abstract}
As we move into the 21st century, increased global competition, rapid developments in the area of information technologies and redesigning of former business processes have deeply affected the way of managing people at workplaces. With the flattening of organizational structures and reduction of management intervention, more responsibilities have been given to the employees for making decisions and managing their daily activities. Besides increasing responsibilities, individuals are expected to be more attached to the goals, objectives and values of their organizations, and also more willing to express their opinions, ideas, suggestions and concerns about workrelated issues. However, building affectively committed workforce and breaking silence by encouraging employees to speak up about critical issues have emerged as crucial management challenges of today's organizations. Numerous theoretical and empirical studies have revealed that attitudinal and behavioral reactions of individuals toward their organizations are mainly influenced by their fairness perceptions. The primary purpose of this study was to investigate the relationship of perceived organizational justice with employee silence and affective commitment. Study was conducted on total 200 white collar employees working in a private sector company. Results indicated that distributive justice has no significant contribution on employee silence and affective commitment. Also, it was revealed that procedural justice has significant positive contribution on acquiescent silence and defensive silence. Finally, interactional justice has been found to be a good predictor of employee silence and affective commitment.
\end{abstract}

Keywords: Organizational Justice, Employee Silence, Affective Commitment

JEL Codes: M1, M10

\section{INTRODUCTION}

As we move into the 21st century, we have witnessed great changes in the world of business. Among the most influential ones of these changes are increased global competition, rapid developments in the area of information technologies and redesigning of former business processes. In fact, these changes have deeply affected the way of doing business and managing people at workplaces. With the flattening of the organizational structures and reduction of management intervention, more responsibilities have been given to the employees for decision making and managing their daily activities. Also, as a result of rapidly changing business needs and role definitions, the traditional "command and control" approach of management has become outdated. Today, employees are no longer managed to comply with the rules, but rather to be committed to the organizational goals and objectives. At the same time, they are expected to be more selfstarting, proactive and preventive in the course of doing their work. Thus, along with their suggestions and innovative ideas, employees' significant effort for the well-being of the organization has become more crucial than ever. However, today's 
managers have some difficulties in encouraging individuals to give voice to their suggestions and innovative ideas, and also building employee commitment (Meyer and Allen, 1997; Fischer, 2004; Morrison, 2014).

First of all, despite the growing importance of upward communication at workplaces, employees are increasingly becoming more reluctant to express their personal opinions and thoughts about work-related issues. During daily activities at work, employees have the chance to see potential problems, inefficient processes, and improvement opportunities. Generally, they have opinions, ideas, suggestions, concerns, and information about these organizational issues. However, most of them do not feel comfortable of speaking to their managers about these issues, and they prefer staying silent. In fact, recent research has shown that silence behavior, which can be defined as the intentional withholding of individuals' workrelated evaluations concerning organizational situations to people who are capable of changing these situations, is becoming pervasive in organizations. Also, it has been argued that this purposeful and conscious behavior can produce negative outcomes for the organizations (Pinder and Harlos, 2001; Van Dyne, Ang, and Botero, 2003; Vakola and Bouradas, 2005; Morrison, 2014).

In addition, for adapting to the rapidly changing business environment, building a committed workforce has emerged as an important issue. Due to the expectation that committed employees will do their best at work, organizations are trying to increase the number of truly loyal employees. Therefore, especially affective commitment has received so much attention from both managers and researchers. In fact, research has shown that affectively committed employees are emotionally attached to the organization's goals, objectives and values. Also, they are more likely to use up significant effort for the benefit of their organizations. Moreover, it has been argued that affectively committed workforce has a significant impact on the overall organizational performance (Mowday, Steers, and Porter, 1979; Meyer and Allen, 1997; Fischer, 2004).

As it is seen, breaking employee silence and building affective commitment are among the most essential management issues which are related to the organizational effectiveness. So, what encourages employees to be more proactive and to speak up about critical issues and problems before they get worse? Also, what makes them affectively committed to their organizations? Actually, from the point of management view, there is no single right answer to these questions. However, numerous theoretical and empirical studies have shown that how employees are treated in workplaces widely affect their beliefs, feelings, thoughts, attitudes, and behaviors. More specifically, attitudinal and behavioral reactions of individuals toward their organizations are mainly influenced by their fairness perceptions. In fact, research has revealed that employees who are allowed to participate in decision making processes, and who are treated with consideration and fairness have stronger affective commitment to their organizations. Also, recent studies have revealed that employee silence is associated with perceived organizational justice, and silence behavior may grow up as a response to perceived injustice (Greenberg, 1990; Meyer and Allen, 1997; Van den Bos, 2001; Pinder and Harlos, 2001).

Based on these previous studies and theoretical evidence, organizational justice has been evaluated as an important determinant of affective commitment and silence of employees at workplaces. Thus, the main purpose of this study is to investigate the impact of perceived organizational justice on employee silence and affective commitment. Also, the study is expected to contribute to the scientific literature by filling the gap concerning the relationships between these variables.

\section{LITERATURE REVIEW}

\section{Organizational Justice}

An act can be defined as fair if most of the individuals perceive it to be morally right and just. From this point of view, Greenberg (1987) has defined organizational justice as the people's perceptions of fairness in the workplace. More specifically, justice is a socially constructed subjective (anything perceived as fair by an employee may be perceived as unfair by another) notion concerning the individuals' evaluations about the appropriateness of a given outcome, process or interpersonal treatment (Colquitt, Conlon, Wesson, Porter, and Ng, 2001; Cropanzano and Greenberg, 1997).

In general, all of the fairness perceptions are related to the actions of an authority in a particular decision making process. Basically, these actions may refer to the decision itself, the process that causes the decision or the interpersonal interactions between the recipient of the decision and the authority. Therefore, the researchers of organizational justice have focused on three major issues: (1) employees' responses to the outcomes they receive, (2) the procedures they experience to obtain these outcomes, and (3) the interpersonal treatments received by the employees during the implementation of these procedures. In the organizational justice literature, these three major issues have been named as distributive, procedural and interactional justice, respectively (Colquitt et al., 2001; Cropanzano and Greenberg, 1997; Bies and Moag, 1986).

\section{Distributive Justice}

The modern roots of distributive justice have been formed by Homans (1961). According to his "rule of distributive justice", all the parties in a social exchange relationship have two main expectations: (1) the rewards of each party in exchange will 
be proportional to the costs of each one, (2) net profits will be proportional to the investments of parties (Cropanzano and Greenberg, 1997). By extending Homans'(1961) conceptualization of distributive justice to the organizational context, Adams (1965) proposed his equity theory. The main structural components of equity theory are inputs and outcomes. Inputs can be described as the contributions of individuals to the exchange, for which they expect fair returns (e.g., education, experience, ability, effort). On the other hand, outcomes can be described as the rewards an individual receives from the exchange. These rewards include factors such as pay and intrinsic satisfaction. Equity theory claims that people compare the ratios of their own perceived work outcomes (rewards) to their own perceived work inputs (contributions) with the corresponding ratios of others (co-workers) (Greenberg and Cohen, 1982; Adams, 1965).

\section{Procedural Justice}

In the early 1970s, the researchers realized the importance of procedures about the distribution of resource rather than the resource itself. They began to claim that individuals' evaluations of allocation decisions are affected not only by what the rewards are, but also by how they are gained. This idea has been developed as procedural justice. From this perspective, the procedures have been considered as the means to provide fair outcomes and justice is defined in terms of fair procedures. Indeed, when employees are given the opportunity to control the procedures that are used in making decisions, they perceive these decisions as fair (Thibaut and Walker, 1975).

In addition, Leventhal (1980) has proposed a more comprehensive list of rules enhancing the fairness perceptions of the procedures. According to Leventhal's (1980) conceptualization, a procedure is perceived as fair if it meets the following six criteria:

(1) The consistency rule states that the procedures used in the allocation of outcomes should be consistent across people and over time.

(2) The bias-suppression rule states that personal opinions and thoughts of decision makers should be minimized during the allocation process.

(3) The accuracy rule states that high quality information should be used in the allocation process, and all the parties should be well-informed.

(4) The correctability rule states that there should be some opportunities to review and revise an unfair decision at any level.

(5) The representativeness rule states that the needs, values and interests of all parties affected by the resource allocation should be taken into consideration during the allocation process.

(6) The ethically rule states that the allocation procedures should be in line with moral and ethical values.

\section{Interactional Justice}

In the organizations, any resource allocation process involves the implementation of a procedure, a final outcome and an interaction between the authority and the recipient of that outcome. Until 1986, the justice literature had covered both outcome and process (procedure); however, the human side of allocation process has been omitted. Therefore, Bies and Moag (1986) have called attention to the interpersonal treatments received by the employees during the implementation of procedures. According to them, in fairness judgements, the proper enactment of a procedure is important as well as the type of that procedure itself. In this context, they have conceptualized interactional justice as the perceived fairness of interpersonal treatment experienced during the implementation of the procedures (Colquitt, 2008; Bies and Moag, 1986; Bies and Shapiro, 1987; Cohen-Charash and Spector, 2001).

In addition, Bies and Moag (1986) have stated that there are four rules enhancing the fairness perceptions of an interpersonal treatment:

(1) Truthfulness rule states that authorities should be straightforward, open and honest in their communications during the enactment of organizational procedures.

(2) Justification rule states that employees should be provided with adequate information about the outcomes of the decision making procedures.

(3) Respect rule states that individuals should be treated with dignity and sincerity, and the decision makers should avoid being rude.

(4) Propriety rule states that authorities should avoid prejudice against employees and asking improper questions about sex, race, age, and religion. 
Numerous research findings have shown that fair and unfair treatments to individuals in organizations widely affect their behaviors and attitudes (Van den Bos, 2001). In this study, of these behaviors and attitudes, employee silence and affective commitment will be discussed in detail. Therefore, employee silence, as the first dependent variable of this research, will be explained in the following section.

\section{Employee Silence}

In management literature, research on employee silence can be traced back to Hirschman (1970). He defined silence as a passive but constructive employee behavior synonymous with loyalty. According to Hirschman, although some of the loyal employees are dissatisfied, these employees may prefer staying in the organization and suffering in silence, since they believe that the current organizational situation will soon get better (Hirschman, 1970).

After Hirschman's widely accepted definition of silence, for many years, subsequent studies have continued to equate the concept of silence with loyalty and endorsement of the status quo (Pinder and Harlos, 2001). Cohen (1990) was probably the first scholar who rejected the notion that silence implies endorsement. He stated that silence may also be a sign of objection. More recently, Pinder and Harlos (2001) defined employee silence as the withholding of individuals' genuine expressions related to their evaluations concerning organizational situations to people who are capable of changing these situations.

Although, for many years, most of the scholars have assumed that employee silence is a simple and unitary concept; recent research has indicated that employee silence is a multidimensional construct that can be caused by a variety of factors. Van Dyne et al. (2003) specified three basic forms of employee silence based on three main employee motives. According to them, if the employee is passive and the primary employee motive is resignation, the resulting behavior is acquiescent silence. In addition, if the employee is proactive, the resulting behavior can be either defensive silence based on selfprotection or pro-social silence based on cooperation (Pinder and Harlos, 2001; Tangirala and Ramanujam, 2008; Van Dyne et al., 2003).

\section{Acquiescent Silence}

Van Dyne et al. (2003) argued that the key feature differentiating silence and voice is the employee's motivation to withhold or express work-related ideas, opinions and information. In this context, silence is generally categorized based on the reasons why employees do not speak up. Following this approach, acquiescent silence can be defined as withholding ideas, opinions and information about work-related improvements, based on resignation. Also, it is a passive behavior closely related to an individual's low involvement. Acquiescently silent employees accept the current organizational situation. Generally, these employees are not willing to speak up, get involved and change the current situation (Van Dyne et al., 2003).

Also, acquiescent silence is an intentional state of being passive and uninvolved. When employees believe that they are unlikely to make any differences, these employees may prefer keeping their suggestions. For instance, employees could withhold work-related ideas during a business meeting since they believe that speaking up is purposeless. In addition, employees might keep opinions and information when they feel that they are not capable of changing the current situation due to organizational policies. In both of these examples, silence is a result of passive acceptance of the status quo (Van Dyne et al., 2003).

\section{Defensive Silence}

As mentioned in the previous sections, organizational scholars emphasized that employee silence can be conceptualized based on the underlying personal emotions for remaining silent. With this perspective, Morrison and Milliken (2000) argued that the key motivator of employee silence is the personal emotion of fear. Similarly, Pinder and Harlos (2001) used the term "quiescent silence" to define deliberate omission based on fear as a dominant personal emotion. Building on these definitions, Van Dyne et al. (2003) described defensive silence as withholding relevant ideas, opinions or information, based on fear, as a form of self-protection (Morrison and Milliken, 2000; Pinder and Harlos, 2001; Van Dyne et al., 2003).

In contrast to acquiescent silence, defensive silence is a proactive and intentional behavior to protect oneself from external threats. Employees remain silent since they are afraid of the events which would occur after speaking up. Although employees are aware of several alternatives to change the current situation, they are not willing to make suggestions for them. Employees choose silence as a personal strategy for their comfort. However, this is a conscious state and these employees are ready to give up their silence with others' assistance (Pinder and Harlos, 2001).

\section{Pro-social Silence}

In addition to acquiescent and defensive silence, Van Dyne et al. (2003) focused on the pro-social forms of employee behavior and they extended the existing conceptualization of silence by proposing a new dimension called "pro-social 
silence". In this context, they defined pro-social silence as withholding work-related ideas, opinions or information for the benefit of other people or the organization, based on cooperation. According to them, pro-social silence is an intentional and proactive behavior that mainly focuses on others' interests (Van Dyne et al., 2003).

When compared to each other, there are some similarities and differences between pro-social silence and defensive silence. Like defensive silence, pro-social silence is based on the awareness of possible alternatives and consciously deciding to remain silent. However, in contrast to defensive silence, pro-social silence is based on cooperative motives, rather than the fear of negative results. From this perspective, an employee could remain silent to protect secret information for the benefit of the organization. Similarly, an employee could have an opinion about a strategic corporate decision and he/she could decide not to discuss this opinion with others. In both of these examples, the employee proactively and intentionally decides not to explain specific information for the benefit of other people (Van Dyne et al., 2003).

\section{The Relationship between Organizational Justice and Employee Silence}

Recent studies have revealed that employee silence is associated with perceived organizational justice. In a qualitative study, Pinder and Harlos (2001) have examined employee silence as a response to perceived injustice in organizations. They have also argued that, besides personality traits such as self-esteem, locus of control, and communication apprehension, there are also situational factors that potentially discourage speaking up. Particularly, they have suggested that one of these situational factors is the climate of organizational injustice. Also, they have stated that, in such an organizational environment, unjustly treated employees tend to stay silent in their relations with the authorities (Pinder and Harlos, 2001).

In addition, Tangirala and Ramanujam (2008) have conducted a survey based quantitative research and examined the moderating effects of procedural justice climate on the relationship between employee silence and its antecedents such as professional commitment and workgroup identification. Specifically, they have reported that employee silence has been found to correlate negatively with employees' professional commitment and their level of identification with the workgroup only when perceived procedural justice climate is high. In contrast, no significant correlation has been found when procedural justice climate is low. Also, to explain the main reasoning behind these findings, they have suggested that employees who perceive procedural justice are less likely to withhold their opinions or concerns about work related issues, since these employees are less likely to be fearful about the adverse consequences of speaking up (Tangirala and Ramanujam, 2008).

More recently, Whiteside and Barclay (2013) have conducted another empirical study examining employee silence as a mediator between overall justice (the combination of distributive, procedural and interactional justice) perceptions and several employee outcomes. Specifically, they have found that acquiescent silence plays a mediating role in the relationships between overall justice perceptions and employee outcomes such as emotional exhaustion, withdrawal, and job performance. Also, defensive silence has partially mediated the relationship between these outcomes excluding job performance and overall justice. Finally, they have concluded that overall justice is an important antecedent for both acquiescent and defensive silence (Whiteside and Barclay, 2013).

As a result, in the light of the literature review and the theoretical and empirical studies mentioned above, the following hypotheses have been developed:

$\mathbf{H}_{1}$ : There is a relationship between perceived organizational justice and employee silence.

$\mathbf{H}_{1 \mathbf{a}}$ : Acquiescent silence is negatively related to perceived organizational justice.

$\mathbf{H}_{\mathbf{1 b}}$ : Defensive silence is negatively related to perceived organizational justice.

$\mathbf{H}_{1 \mathbf{c}}$ : Pro-social silence is positively related to perceived organizational justice.

Another purpose of this study is to investigate the relationship between affective commitment and organizational justice. Hereafter, organizational commitment, as the second dependent variable of this study, and its relationship with perceived organizational justice will be discussed.

\section{Organizational Commitment}

In the fields of management and organizational behavior, research on the topic of commitment can be traced back to the side-bet theory proposed by Becker (1960). In his theory, Becker (1960, p.32) stated that "commitments come into being when a person, by making a side bet, links extraneous interests with a consistent line of activity". The term "side-bet" is used to refer to the accumulation of investments (e.g., time, effort, organization-specific skills, work friendships, and public image) that would be lost in case of leaving the organization. Over a period of time, accumulated investments make it more difficult for the employee to disengage from a consistent course of action. In the context of organizational commitment, the consistent course of action is remaining as a member of the company. In other words, the threat of losing personal 
investments, along with a perceived lack of alternatives, makes employees committed to the organization (Becker, 1960; Cohen, 2007).

In a more comprehensive manner, Mowday et al. $(1979$, p.226) described organizational commitment as "the relative strength of an individual's identification with and involvement in a particular organization". According to these researchers, organizational commitment has at least three factors: (1) Being attached to the organization's goals, objectives and values, (2) Using up significant effort for the benefit of the organization, and (3) Strongly willing to stay as a member of the organization (Mowday et al., 1979).

From a different perspective, Wiener (1982) described organizational commitment as a behavior that meets organizational goals and interests, resulting from the internalization of normative beliefs and pressures. According to this approach, committed employees exhibit this certain behavior not because they think that it is beneficial, but because they believe that it is the "moral" and "right" thing to do (Wiener, 1982).

The definitions above can be categorized into some general themes such as emotion-based attachment, cost-based attachment and obligation-based attachment to the organization. Within this context, Meyer and Allen (1991) proposed a three-component model for organizational commitment. According to this model, organizational commitment has been conceptualized in terms of three separate themes: emotional attachment to the organization, perceived costs of leaving the organization, and obligation to remain as a member of the organization. Thus, the three components of organizational commitment are affective, continuance, and normative commitment, respectively (Meyer and Allen, 1991).

Firstly, affective commitment refers to the employee's "emotional attachment to, identification with, and involvement in the organization" (Meyer and Allen, 1991, p.67). Since they are emotionally attached to their organizations, affectively committed employees "want to" remain with the organization. On the other hand, continuance commitment refers to "the awareness of the costs associated with leaving the organization" (Meyer and Allen, 1991, p.67). In addition, continuance commitment is related with the lack of alternatives. Employees feel that they "have to" stay in the organization because they need the benefits provided by the organization. Lastly, normative commitment is based on the feelings of obligation to stay in the organization. Normatively committed employees feel that they "ought to" remain with the organization (Meyer and Allen, 1991; Meyer and Allen, 1997).

When compared to normative and continuance commitment, there is a significant and stronger correlation between affective commitment and a wide range of organizational outcome variables such as turnover, absenteeism, job performance and organizational citizenship behavior (Meyer and Herscovitch, 2001; Meyer et al., 2002). Also, it has been argued that only affective commitment can buffer the negative impacts of work stressors on employee well-being and health (Meyer et al., 2002). On the other hand, it has been questioned whether or not continuance commitment is a form of employee commitment, since it has some devastating behavioral consequences for the organization (Abbott, White and Charles, 2005). Taken these findings together, it appears that continuance commitment is a less productive component of organizational commitment (Wasti, 2002). Also, normative commitment is strongly correlated with affective commitment in terms of its behavioral consequences (Meyer and Allen, 1991). As a result, it has been evaluated that, of the three components, affective commitment is the strongest and the most consistent predictor of desired organizational outcomes (Meyer and Allen, 1997). Therefore, only affective commitment will be investigated in this study.

\section{The Relationship between Organizational Justice and Effective Commitment}

Research has revealed that affective commitment which is a type of attitudinal reaction toward the whole organization has been mainly related to perceived procedural justice. Within this context, Cohen-Charash and Spector (2001) have argued that all three components of justice are related to affective commitment; however, procedural justice has the strongest correlation. Similarly, Colquitt et al. (2001) have conducted a comprehensive study to shed light on the relationship between justice dimensions and several organizational outcomes including affective commitment. Specifically, they have found that there is a significant correlation between affective commitment and all types of organizational justice. Also, they have stated that procedural justice has the strongest correlation, followed by distributive justice and interactional justice (Cohen-Charash and Spector, 2001; Colquitt et al., 2001).

Also, it has been argued that affective commitment has the most consistent and strongest correlations with work experiences. Therefore, the development of affective commitment is expected to be influenced by the relations between employees and their supervisors. Indeed, research has revealed that employees who are allowed to participate in decision making processes, and who are treated with consideration and fairness have stronger affective commitment to their organizations (Meyer and Allen, 1997).

Based on the previous studies mentioned above, the following hypotheses have been developed:

$\mathbf{H}_{\mathbf{2}}$ : There is a relationship between perceived organizational justice and affective commitment. 
$\mathbf{H}_{\mathbf{2 a}}$ : Perceived distributive justice is positively related to affective commitment.

$\mathbf{H}_{\mathbf{2 b}}$ : Perceived procedural justice is positively related to affective commitment.

$\mathbf{H}_{2 \mathbf{c}}$ : Perceived interactional justice is positively related to affective commitment.

As a result, in the light of the theoretical framework drawn above, Figure 1 depicts the theoretical model of this study.

Figure 1: The Theoretical Model

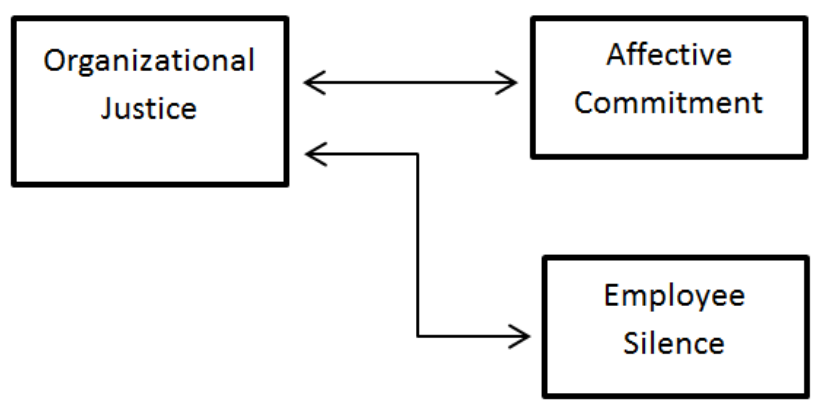

\section{DATA AND METHODOLOGY}

\section{Sample}

This study was conducted in a well-known private sector organization located in Istanbul. The sample consists of 200 white collar employees who have voluntarily participated to the study. Also, the sample consists of both females and males. There are no other special criteria for the employees who are chosen as the sample. In other words, convenience sampling has been used for the data collection.

\section{Measurement Instruments}

The construct of organizational justice is measured by the scale developed by Niehoff and Moorman (1993). According to this scale, organizational justice is investigated in terms of three dimensions measuring perceptions of distributive justice, procedural justice and interactional justice. Firstly, distributive justice is measured with 5 items assessing the fairness perceptions of work outcomes such as pay level, work load, and work schedule. An example of the items included in distributive justice subscale is "I think that my level of pay is fair". Secondly, procedural justice is measured using 6 items assessing the fairness perceptions of the formal procedures which are used in making decisions. A sample item included in procedural justice subscale is "Before making decisions about work, my executives collect accurate and complete information". Finally, interactional justice is measured with 9 items assessing the perceived fairness of interpersonal treatment experienced during the implementation of the procedures. An example of the items included in interactional justice subscale is "While decisions are taken about my job, my executives are honest and sincere to me".

Affective commitment is measured using 6-item part of organizational commitment scale developed by Meyer and Allen (1991). The third section of the questionnaire includes these 6 items to measure affective commitment of employees. In fact, affective commitment assesses the feelings of employees about remaining as a member of the company. A sample item included in affective commitment scale is "I would be very happy to spend the rest of my career with this organization". Also, the scale includes some reverse scored items such as "I do not feel emotionally attached to this organization".

The construct of employee silence is measured by the scale developed by Van Dyne et al. (2003). According to this scale, employee silence has three dimensions, namely acquiescent silence, defensive silence, and pro-social silence. Firstly, acquiescent silence is measured with 5 items assessing the silence behavior of employees based on resignation. An example of the items included in acquiescent silence subscale is "I passively keep ideas about solutions to problems to myself". Secondly, defensive silence is measured using 5 items assessing the silence behavior of employees based on self-protection. A sample item included in defensive silence subscale is "I do not speak up and suggest ideas for change, based on fear". Finally, pro-social silence is measured with 5 items assessing the silence behavior of employees based on cooperation. An example of the items included in pro-social silence subscale is "I protect proprietary information in order to benefit the organization".

In order to eliminate the central tendencies, a six-point response scale ranging from "strongly disagree" (1) to "strongly agree" (6) is used for organizational justice, affective commitment and employee silence tests. 


\section{FINDINGS AND DISCUSSIONS}

\section{Respondents' Profile}

The sample consists of 116 males and 84 females. The ages of these individuals range from 22 to 55 years. Nearly half of them are married. A very small percentage of the participants (2.5\%) have a high school degree. In addition, $78 \%$ of the sample has a bachelor's degree, and the remaining $19.5 \%$ has a postgraduate degree. Also, the sample includes a wide tenure range between $1-29$ years, and total work experience range between $1-30$ years. Finally, most of the respondents are business analysts and software engineers. The details of descriptive statistics are shown below in Table 1.

Table 1: Descriptive Statistics of the Sample $(n=200)$

\begin{tabular}{|c|c|c|c|c|c|}
\hline Variable & $\mathbf{N}$ & Percentage & Mean & Standard Deviation & Range \\
\hline \multicolumn{6}{|l|}{ Gender } \\
\hline Female & 84 & 42.00 & & & \\
\hline Male & 116 & 58.00 & & & \\
\hline Age & 200 & & 31.42 & 6.44 & $22-55$ \\
\hline \multicolumn{6}{|l|}{ Marital Status } \\
\hline Married & 97 & 48.50 & & & \\
\hline Single & 103 & 51.50 & & & \\
\hline \multicolumn{6}{|l|}{ Education } \\
\hline High School & 5 & 2.50 & & & \\
\hline University & 156 & 78.00 & & & \\
\hline Post Graduate & 39 & 19.50 & & & \\
\hline Tenure & 200 & & 6.13 & 6.79 & $1-29$ \\
\hline Total Experience & 200 & & 8.74 & 7.07 & $1-30$ \\
\hline \multicolumn{6}{|l|}{ Position } \\
\hline Business Analyst & 77 & 38.50 & & & \\
\hline Software Engineer & 90 & 45.00 & & & \\
\hline Manager & 19 & 9.50 & & & \\
\hline Specialist & 14 & 7.00 & & & \\
\hline
\end{tabular}

\section{Reliability Analysis}

Reliability analysis was conducted for organizational justice, employee silence and affective commitment scales and subscales. The results have shown that all the scales and subscales have reliability coefficients above 0.83 . That is, all of them have fairly high internal consistencies when compared to the generally accepted sufficiency level of 0.70 . The details of this analysis including means, standard deviations and reliability coefficients of research variables are shown below in Table 2 .

Table 2: Means, Standard Deviations and Reliability Coefficients of Research Variables

\begin{tabular}{|c|c|c|c|}
\hline \hline \multirow{2}{*}{ Scale } & Mean & Standard Deviation & Cronbach's Alpha \\
& & & .958 \\
\hline \hline Organizational Justice (Overall) & 3.5810 & .80314 & .869 \\
\hline Distributive Justice & 3.6490 & .84485 & .905 \\
\hline Procedural Justice & 3.3058 & .92439 & .952 \\
\hline Interactional Justice & 3.7267 & .90266 & .831 \\
\hline \hline Employee Silence (Overall) & 3.1683 & .55593 & .895 \\
\hline Acquiescent Silence & 2.3800 & .82401 & .934 \\
\hline Defensive Silence & 2.1800 & .83251 & .843 \\
\hline \hline Pro-social Silence & 4.9450 & .98510 & .88935 \\
\hline \hline
\end{tabular}


It should be noted that all these values have been calculated with the original items of the scales. The reliability coefficients of organizational justice and employee silence scales will be re-calculated after clarifying the factor structures of these constructs. The following section will explain the details of factor analysis.

\section{Factor Analysis of Organizational Justice and Employee Silence}

Few rotations were made to obtain the best result in factor analysis. Only the item 20 of organizational justice scale was left out of the analysis due to crossloading. It was loaded on both procedural and interactional justice factors. The original item was "My executives explain very clearly any decision made about my job". The remaining 19 items were loaded on three factors. These three factors explain $71.082 \%$ of the total variance. Also, the resulting factors were named as distributive justice, procedural justice, and interactional justice similar to Niehoff and Moorman's (1993) organizational justice dimensions. The composition of items in each factor was quite satisfactory, since all of them were loaded on the factors compatible with the original dimensions of the scale. The results of the factor analysis are shown below in Table 3 . In addition to factor loadings, reliability coefficients calculated with the items of factors were also included in the table.

Table 3: Results of the Factor Analysis of Organizational Justice Scale

\begin{tabular}{|c|c|}
\hline Factor 1: Interactional Justice & $\begin{array}{l}\text { Factor } \\
\text { Loadings }\end{array}$ \\
\hline 15. When decisions are made about my job, the executives deal with me in a truthful manner. & .812 \\
\hline 14. When decisions are made about my job, the executives are sensitive to my personal needs. & .808 \\
\hline 13. When decisions are made about my job, the executives treat me with respect and dignity. & .775 \\
\hline 19. When making decisions about my job, my executives offer explanations that make sense to me. & .761 \\
\hline 16. When decisions are made about my job, my executives show concern for my rights as an employee. & .730 \\
\hline $\begin{array}{l}\text { 17. Concerning decisions made about my job, my executives discuss the implications of the decisions } \\
\text { with me. }\end{array}$ & .726 \\
\hline 18. My executives offer adequate justification for decisions made about my job. & .714 \\
\hline 12. When decisions are made about my job, the executives treat me with kindness and consideration. & .695 \\
\hline Factor 2: Procedural Justice & \\
\hline 9. Executives clarify decisions and provide additional information when requested by employees. & .801 \\
\hline 10. All job decisions are applied consistently across all affected employees. & .736 \\
\hline 8. To make job decisions, executives collect accurate and complete information. & .711 \\
\hline 11. Employees are allowed to challenge or appeal job decisions made by the executives. & .692 \\
\hline 7. Executives make sure that all employee concerns are heard before job decisions are made. & .644 \\
\hline 6. Job decisions are made by the executives in an unbiased manner. & .568 \\
\hline Factor 3: Distributive Justice & \\
\hline 3. I consider my work load to be quite fair. & .833 \\
\hline 1. My work schedule is fair. & .797 \\
\hline 4. Overall, the rewards I receive here are quite fair. & .742 \\
\hline 5. I feel that my job responsibilities are fair. & .689 \\
\hline 2. I think that my level of pay is fair. & .674 \\
\hline \multicolumn{2}{|l|}{ Kaiser-Meyer-Olkin Measure of Sampling Adequacy: .939 } \\
\hline Bartlett's Test of Sphericity: .000; Chi-Square: 3209.561 ; & \\
\hline
\end{tabular}

Secondly, employee silence was factor analyzed to determine the dimensional structure of the scale. 15 items of employee silence measure were entered into factor analysis. Only the item 5 of employee silence scale was left out due to crossloading. It was loaded on both acquiescent and defensive silence factors. The original item was "This employee withholds ideas about how to improve the work around here, based on being disengaged". The remaining 14 items were loaded on three factors. These three factors explain $77.258 \%$ of the total variance. Also, the resulting factors were named as acquiescent silence, defensive silence, and pro-social silence. All of the items were loaded on the factors compatible with the original dimensions of the scale developed by Van Dyne et al. (2003).

In addition, the reliability coefficients were high when compared to the accepted sufficiency level of 0.70 , indicating that the items of this scale have fairly high internal consistencies. The details of the factor analysis are exhibited below in Table 4. 
Table 4: Results of the Factor Analysis of Employee Silence Scale

\begin{tabular}{|c|c|}
\hline Factor 1: Pro-social Silence & $\begin{array}{l}\text { Factor } \\
\text { Loadings }\end{array}$ \\
\hline 12. This employee protects proprietary information in order to benefit the organization. & .934 \\
\hline $\begin{array}{l}\text { 15. This employee protects confidential organizational information appropriately, based on concern for } \\
\text { the organization. }\end{array}$ & .927 \\
\hline 14. This employee refuses to divulge information that might harm the organization. & .915 \\
\hline 13. This employee withstands pressure from others to tell organizational secrets. & .875 \\
\hline 11. This employee withholds confidential information, based on cooperation. & .791 \\
\hline Factor 2: Defensive Silence & \\
\hline 9. This employee avoids expressing ideas for improvements, due to self-protection. & .866 \\
\hline 10. This employee withholds his/her solutions to problems because he/she is motivated by fear. & .830 \\
\hline 7. This employee withholds relevant information due to fear. & .811 \\
\hline 8. This employee omits pertinent facts in order to protect him/her self. & .788 \\
\hline 6. This employee does not speak up and suggest ideas for change, based on fear. & .738 \\
\hline Factor 3: Acquiescent Silence & \\
\hline 2. This employee passively withholds ideas, based on resignation. & .837 \\
\hline 3. This employee passively keeps ideas about solutions to problems to him/her self. & .821 \\
\hline 1. This employee is unwilling to speak up with suggestions for change because he/she is disengaged. & .782 \\
\hline $\begin{array}{l}\text { 4. This employee keeps any ideas for improvement to him/her self because he/she has low self-efficacy } \\
\text { to make a difference. }\end{array}$ & .715 \\
\hline \multicolumn{2}{|l|}{ Kaiser-Meyer-Olkin Measure of Sampling Adequacy: .895 } \\
\hline Bartlett's Test of Sphericity: .000; Chi-Square: 2307.439; & \\
\hline
\end{tabular}

\section{Correlation Analysis}

Correlations related to all factors of independent variable (organizational justice), and dependent variables (employee silence, affective commitment) are exhibited in Table 5. Generally, all significant coefficients indicate low to moderate relationships.

Table 5: Correlations of all dependent and independent variables

\begin{tabular}{cccccccc}
\hline Variable & $\mathbf{1}$ & $\mathbf{2}$ & $\mathbf{3}$ & $\mathbf{4}$ & $\mathbf{5}$ & $\mathbf{6}$ & $\mathbf{7}$ \\
\hline 1 & OJ1 & OJ2 & OJ3 & ES1 & ES2 & ES3 & \\
\hline 2 & 1 & & & & & & \\
3 & $.797^{* *}$ & 1 & & & & & \\
4 & $.613^{* *}$ & $.606^{* *}$ & 1 & & & \\
5 & $.264^{* *}$ & $.204^{* *}$ & $.212^{* *}$ & 1 & & & \\
6 & $-.191^{* *}$ & -.067 & -.096 & $-.165^{*}$ & 1 & & \\
7 & -.021 & .117 & -.002 & $-.184^{* *}$ & $.682^{* *}$ & 1 & \\
\hline
\end{tabular}

** Correlation is significant at the 0.01 level (2-tailed).

* Correlation is significant at the 0.05 level (2-tailed).

Organizational Justice Factors; OJ1: Interactional Justice, OJ2: Procedural Justice, OJ3: Distributive Justice

Employee Silence Factors; ES1: Pro-social Silence, ES2: Defensive Silence, ES3: Acquiescent Silence

Commitment: AC: Affective Commitment

The results of correlation analysis showed that there is no significant correlation between acquiescent silence and organizational justice factors $(r=-.021, r=.117, r=-.002$ respectively, $p>.05)$. In addition, there is a significant, but weak, negative correlation between defensive silence and perceived interactional justice $(r=-.191, p<.01)$. However, there is no 
significant correlation between defensive silence and the other factors of organizational justice $(r=.067, r=.096$ respectively, $p>.05$ ). On the other hand, test results showed that there is a significant and positive correlation between pro-social silence and organizational justice factors $(r=.264, r=.204, r=.212$ respectively, $p<.01)$.

Also, the results of the correlation analysis indicated that there is a significant and positive correlation between affective commitment and organizational justice factors $(r=.427, r=.371, r=.349$ respectively, $p<.01)$.

\section{Regression Analysis}

In order to investigate the relationship between organizational justice and employee silence factors, multiple regression analysis was conducted for organizational justice on each factor of employee silence separately. First of all, the contribution of organizational justice on pro-social silence was tested. The results of this multiple regression analysis were shown below in Table 6.

Table 6: Results of Multiple Regression Analysis for Testing the Main Effect of Organizational Justice on Pro-social Silence

$$
\text { Dependent Variable : Pro-social Silence }
$$

\begin{tabular}{lccc}
\hline Independent Variables: & $\mathbf{B}$ & $\mathbf{t}$ value & $\mathrm{p}$ value \\
Interactional Justice & .247 & 2.084 & .038 \\
Procedural Justice & -.046 & -.395 & .693 \\
Distributive Justice & .089 & .993 & .322 \\
$\mathbf{R}=.273 ; \mathbf{R}^{2}=.075 ; \mathbf{F}$ value $=5.263 ; \boldsymbol{p}$ value $=.002$ & & \\
\hline
\end{tabular}

According to these results, no significant relationship was found between pro-social silence and the two factors of organizational justice, namely procedural and distributive justice. However, significant and positive effect of interactional justice was found on pro-social silence $(\beta=.247, p<.05)$.

Thus, hypothesis $\mathbf{H}_{1 \mathbf{c}}$, stating "Pro-social silence is positively related to perceived organizational justice" has found partial support with the findings of positive relationship between interactional justice and pro-social silence $(\beta=.247, p<.05)$.

Secondly, the contribution of perceived organizational justice on defensive silence was tested using multiple regression analysis. The results of the analysis were exhibited in Table 7.

Table 7: Results of Multiple Regression Analysis for Testing the Main Effect of Organizational Justice on Defensive Silence

Dependent Variable : Defensive Silence

\begin{tabular}{lccc}
\hline Independent Variables: & $\mathbf{B}$ & t value & $\mathbf{p}$ value \\
Interactional Justice & -.375 & -3.140 & $\mathbf{0 0 2}$ \\
Procedural Justice & .238 & 2.010 & $\mathbf{0 4 6}$ \\
Distributive Justice & -.010 & -.112 & .911 \\
$\mathbf{R}=.238 ; \mathbf{R}^{2}=.057 ; \mathbf{F}$ value $=3.930 ; \mathbf{p}$ value $=.009$ & & \\
\hline
\end{tabular}

According to the results, no significant relationship was found between defensive silence and distributive justice. However, significant negative effect of interactional justice was found on defensive silence $(\beta=-.375, p<.01)$. Also, it was found that there is a significant and positive effect of procedural justice on defensive silence $(\beta=.238, p<.05)$.

Hypothesis $\mathbf{H}_{\mathbf{1}}$, stating "Defensive silence is negatively related to perceived organizational justice" has found partial support with the findings of negative relationship between interactional justice and defensive silence $(\beta=-.375, p<.01)$.

Finally, the contribution of perceived organizational justice on acquiescent silence was tested using multiple regression analysis. The results of this analysis were shown in Table 8. 
Table 8: Results of Multiple Regression Analysis for Testing the Main Effect of Organizational Justice on Acquiescent Silence

\begin{tabular}{lccc}
\hline \multicolumn{2}{l}{ Dependent Variable : Acquiescent Silence } & & \\
\hline Independent Variables: & $\boldsymbol{\beta}$ & $\mathbf{t}$ value & $\mathbf{p}$ value \\
Interactional Justice & -.293 & -2.447 & $\mathbf{0 1 5}$ \\
Procedural Justice & .384 & 3.231 & $\mathbf{0 0 1}$ \\
Distributive Justice & -.055 & -.609 & .543 \\
$\mathbf{R}=.226 ; \mathbf{R}^{2}=.051 ; \mathbf{F}$ value $=3.520 ; \mathbf{p}$ value $=.016$ & & \\
\hline
\end{tabular}

According to these results, no significant relationship was found between acquiescent silence and distributive justice. However, significant negative effect of interactional justice was found on acquiescent silence $(\beta=-.293, p<.05)$. Also, it was found that there is a significant and positive effect of procedural justice on acquiescent silence $(\beta=.384, p<.01)$.

Hypothesis $\mathbf{H}_{1 a}$, stating "Acquiescent silence is negatively related to perceived organizational justice" has found partial support with the findings of negative relationship between interactional justice and acquiescent silence $(\beta=-.293, p<.05)$.

In summary, no significant relationship was found between distributive justice and employee silence. Also, the results revealed that interactional justice and procedural justice have partial contribution on employee silence. Thus, the main hypothesis $\mathbf{H}_{1}$, stating "There is a relationship between perceived organizational justice and employee silence" was partially supported.

In addition, to test the second hypothesis of the study; the relationship between organizational justice and affective commitment has been investigated using multiple regression analysis. The results of this analysis were exhibited in Table 9 .

Table 9: Results of Multiple Regression Analysis for Testing the Main Effect of Organizational Justice on Affective Commitment

\begin{tabular}{lccc}
\hline \multicolumn{2}{l}{ Dependent Variable : Affective Commitment } & & \\
\hline Independent Variables: & $\boldsymbol{\beta}$ & $\mathbf{t}$ value & $\mathbf{p}$ value \\
Interactional Justice & .314 & 2.843 & .005 \\
Procedural Justice & .040 & .368 & .713 \\
Distributive Justice & .133 & 1.586 & .114 \\
$\mathbf{R}=.442 ; \mathbf{R}^{2}=.195 ;$ F value $=15.858 ; \boldsymbol{p}$ value $=.000$ & & \\
\hline
\end{tabular}

According to these results, no significant relationship was found between affective commitment and the two factors of organizational justice, namely procedural and distributive justice. However, significant and positive effect of interactional justice was found on affective commitment $(\beta=.314, p<.01)$.

Thus, hypothesis $\mathbf{H}_{2 \mathbf{c}}$, stating "Perceived interactional justice is positively related to affective commitment" was accepted with the findings of positive relationship between interactional justice and affective commitment $(\beta=.314, p<.01)$. However, hypothesis $\mathbf{H}_{2 \mathbf{a}}$, stating "Perceived distributive justice is positively related to affective commitment", and hypothesis $\mathbf{H}_{\mathbf{2 b}}$, stating "Perceived procedural justice is positively related to affective commitment" were rejected.

Also, the main hypothesis $\mathbf{H}_{\mathbf{2}}$, stating "There is a relationship between perceived organizational justice and affective commitment" has found partial support with the findings of significant positive relationship between interactional justice factor and affective commitment $(\beta=.314, p<.01)$.

\section{CONCLUSION}

Numerous theoretical and empirical studies have been conducted to determine the dynamics behind employee attitudes and behaviors. These studies have shown that attitudinal and behavioral reactions of individuals toward their organizations are mainly influenced by their fairness perceptions (Greenberg, 1990; Van den Bos, 2001). More specifically, research has revealed that employees who are allowed to participate in decision making processes, and who are treated with consideration and fairness have stronger affective commitment to their organizations (Meyer and Allen, 1997). Also, recent studies have revealed that employee silence behavior may grow up as a response to perceived injustice (Pinder and Harlos, 
2001). With these studies in mind, the primary purpose of this study was to investigate the relationship of perceived organizational justice (fairness perceptions) with employee silence and affective commitment.

According to regression analysis, significant and negative effect of interactional justice was found on acquiescent silence and defensive silence. This is a reasonable and consistent finding. It means that silence behavior of employees is influenced by the perceptions of the quality of interpersonal relations with their executives. In other words, when the employees perceive a higher level of politeness, dignity, and respect from their executives, they become more willing to speak up about organizational issues. Otherwise, they remain silent based on resignation or fear, as a form of self-protection. In addition, significant and positive effect of interactional justice was found on pro-social silence. That is, when the employees experience a high quality of interpersonal treatment, they become more willing to remain silent based on cooperative motives. In fact, pro-socially silent employees intentionally decide not to explain specific information for the benefit of other people or the organization (Van Dyne et al., 2003).

Moreover, the results of regression analysis indicated that there is a significant and positive effect of procedural justice perceptions on acquiescent silence and defensive silence. This means that when outcome allocation procedures of the organization are perceived as fair, employees become more reluctant to speak up, and they prefer staying silent. At first glance, that seemed as an unexpected finding, however, it was not. Demiralay and Lorcu (2015) had found similar results. To clarify the results, they argued that although employees perceive salaries, promotions and awards as fair, they could prefer being silent due to fear of losing what they have already achieved. In other words, increase in the perceptions of procedural justice also increases silence behaviors of employees based on fear of losing acquired rights.

Another finding of regression analysis was concerning the relationship between organizational justice and affective commitment. In this study, contrary to the relevant literature which indicated that affective commitment is highly related to all three types of organizational justice (Meyer and Allen, 1997; Cohen-Charash and Spector, 2001; Colquitt et al., 2001), no significant relationship was found between affective commitment and the two types of organizational justice, namely procedural and distributive justice. However, significant and positive effect of interactional justice was found on affective commitment. This means that increase in the perceived quality of interpersonal treatment also increases affective commitment of employees. In other words, higher perceived level of dignity and respect in the relations with the managers increases emotional attachment of employees to their organization.

To sum up, the results of regression analysis indicated that distributive justice has no significant contribution on employee silence and affective commitment. Also, it was revealed that procedural justice has significant positive contribution on acquiescent silence and defensive silence. Finally, interactional justice has been found to be a good predictor of employee silence and affective commitment. Thus, hypothesis $\mathbf{H}_{\mathbf{1}}$, stating "There is a relationship between perceived organizational justice and employee silence", and hypothesis $\mathbf{H}_{\mathbf{2}}$, stating "There is a relationship between perceived organizational justice and affective commitment" have found partial support with these findings.

\section{Limitations of the Study}

Like any other empirical studies, this research has some limitations that should be noted. First of all, the convenient sample of this study consists of only 200 voluntarily participants representing a small part of the company and also the sector. Since the sample size is small, it is not possible to generalize the results. Also, this study has been conducted in only one company. Therefore, it would not be wrong to say that some of the findings were likely to be company-specific. In fact, a much larger sample size including many companies would be better to obtain more consistent and generalizable results.

Another limitation of this study is the fact that all the data in the survey was gathered via self-reports of participants. Collecting data via self-report questionnaires may increase common method variance. In such a survey, respondents may give exaggerated answers and manipulate the results. Therefore, collecting data from multiple sources including co-workers and supervisors would reveal more reliable findings. In addition, only the voluntary employees participated to the study and answered the questionnaire. This may also create a self-selection bias.

Finally, the time horizon of this study is cross-sectional. Since cross-sectional studies offer a snapshot of a single moment, these studies may not give exact information about cause-and-effect relationships between variables. Instead, longitudinal studies are used to detect the changes in research variables over a period of time and to investigate the causality direction of research variables. Therefore, a longitudinal study would reveal more accurate results about the causal effect of perceived organizational justice on employee silence and affective commitment.

\section{Suggestions for Future Research}

Communication is vital for the success of organizations (Vakola and Bouradas, 2005). If employee silence does occur, communication suffers which in turn harms the overall functioning of the organization. Therefore, employee silence started to become a popular topic for both managers and organizational behavior scholars. However, there is still little academic 
research on this phenomenon. In a recent study, Brinsfield (2013) emphasized the need for empirical studies on this topic to improve our understanding of the nature of silence. Indeed, when the increasing importance of breaking silence at workplaces is taken into account, it is obvious that more comprehensive studies should be conducted to examine different motives behind the silence behavior of employees and to explore the nature and scope of these silence motives.

In addition, research on organizational commitment usually focuses on affective, continuance and normative commitment as separate components. However, Meyer and Allen (1991) argued that employees may have all three forms of commitment, simultaneously, in varying degrees. More recently, Meyer and Herscovitch (2001) emphasized that organizational commitment should be evaluated as combinations of the three commitment forms. Also, they argued that varying levels of three components creates a distinct commitment profile for individuals. However, little is known about the combined influence of commitment forms on desirable work outcomes. Therefore, the coexistence of the three components needs to be investigated in detail for a more realistic and complete understanding of organizational commitment (Wasti, 2005).

Moreover, an impressive finding of this study was the fact that only interactional justice has great contribution to enhancing affective commitment, and breaking employee silence. This result shows that employees mostly care about the quality of interpersonal relations with their executives. It is obvious that interactional justice is all about the behavior of the leaders. Therefore, to investigate the role of leadership styles on fairness perceptions of employees, additional research should be conducted with a theoretical model including leadership styles as a moderating variable.

Finally, and the most importantly, almost all researchers and managers focused on the consequences of fairness perceptions in terms of employee attitudes and behaviors. However, investigating all these consequences is not adequate for organizations to create a fair and positive work environment. There is one more question that needs to be answered: "Why do managers treat employees unfairly?" (Bies, 2015) In order to answer this question, further research which examine justice as a dependent variable should be conducted. Such a study would be valuable to draw the overall big picture of organizational justice.

\section{Managerial Implications}

Besides its contribution to the scientific literature, this study has some practical implications that should be discussed here. First of all, climate of silence has a great effect on the ability of an organization to detect potential problems and improve inefficient business processes. Therefore, it becomes essential to create a work environment where employees feel comfortable of speaking to their managers about organizational issues. Employees usually prefer staying silent when they feel that they are not capable of changing the current situation, and when they are afraid of the negative consequences of speaking up. At this point, organizations should develop and maintain formal mechanisms which ensure communication opportunities and encourage employees to speak up. In addition, top managers and supervisors should engage in attitudes and behaviors that would create a trustful workplace. When the employees feel safer to express their views, opinions and ideas, they will probably not choose silence (Vakola and Bouradas, 2005; Morrison, 2014).

Secondly, the results of recent studies suggest that affectively committed employees work harder and perform better than their co-workers. Therefore, building affectively committed workforce has become crucial for the survival of modern organizations. In this regard, human resources executives should develop proper strategies to retain employees by increasing their emotional attachment to the organization. In addition, because of the fact that affective commitment is largely the result of work experiences, a positive work environment should be provided to the employees. Moreover, in order to maintain a deeper level of affective commitment, organizations should not only focus on the turnover intentions, they should also concentrate on the strategies for developing a fair and supportive work environment in terms of rewards, promotions and interpersonal relations (Cohen, 2007).

Finally, there is no doubt that individuals always care about justice. Therefore, organizations should take appropriate actions for the effective management of fairness in the workplace. For instance, rewards should be distributed fairly to the employees in proportion to the value added. In addition, consistent and un-biased procedures should be implemented to ensure fair outcomes. More specifically, as an important driver in predicting employee silence and affective commitment, the perceived fairness of interpersonal treatment should be carefully taken into account by the organizations. Top managers and supervisors should treat employees with sensitivity and politeness. Also, they should be open and honest in their communications with the employees. Furthermore, training programs for managers should be organized to make them aware of the negative consequences of unfair treatments and enhance fairness perceptions in the workplace. As a matter of fact, managing fairness perceptions effectively can help organizations to build affectively committed workforce and breaking silence by encouraging employees to speak up about critical issues (Whiteside and Barclay, 2013). 


\section{REFERENCES}

Abbott, G. N., White F. A., and Charles M. A. (2005). "Linking values and organizational commitment: A correlational and experimental investigation in two organizations", Journal of Occupational and Organizational Psychology, 78:531-551

Adams, J. S. (1965). "Inequity in Social Exchange”, In L. Berkowitz (Eds.), Advances in experimental social psychology (Vol. 2, pp. 267-299), New York: Academic Press.

Becker, H. S. (1960). "Notes on the Concept of Commitment". American Journal of Sociology, 66: 32-42.

Bies, R.J. (2015). "Interactional Justice: Looking Backward, Looking Forward”, In Cropanzano, R., Ambrose, M.L. (Eds.), The Oxford Handbook of Justice in the Workplace (pp. 89-107). Oxford University Press.

Bies, R. J., and Moag, J. F. (1986). "Interactional justice: Communication criteria of fairness". In R. J. Lewicki, B. H. Sheppard, and M. H. Bazerman (Eds.), Research on negotiations in organizations (Vol. 1, pp. 43-55). Greenwich, CT: JAI Press.

Bies, R.J. and Shapiro, D.L. (1987). "Interactional Fairness Judgments: The Influence of Causal Accounts", Social Justice Research, 1: 199218.

Brinsfield, C.T. (2013). "Employee silence motives: Investigation of dimensionality and development of measures", Journal of Organizational Behavior, 34(5): 671-697.

Cohen, A. (2007). "Commitment before and after: An evaluation and reconceptualization of organizational commitment", Human Resource Management Review, 17: 336-354.

Cohen, R. L. (1990). “Justice, voice and silence”, Paper presented at the International Conference on Social Science and Societal Dilemmas, Utrecht, The Netherlands.

Cohen-Charash, Y., and Spector, P. E. (2001). "The role of justice in organizations: A meta-analysis", Organizational Behavior and Human Decision Processes, 86(2), 278-321.

Colquitt, J.A. (2001). "On the Dimensionality of Organizational Justice: A Construct Validation of a Measure", Journal of Applied Psychology, 86:386-400.

Colquitt, J.A. (2008). "Two Decades of Organizational Justice: Findings, Controversies, and Future Directions", In J. Barling and C.L. Cooper (Eds.), The Sage Handbook of Organizational Behavior Volume 1: Micro approaches (pp. 73-88). London, UK: Sage Publications.

Colquitt, J. A., Conlon, D.E., Wesson, M.Y., Porter, C., and Ng, K.Y., (2001). "Justice at the Millennium: A Meta-Analytic Review of 25 Years of Organizational Justice Research", Journal of Applied Psychology, 86(3), 425-445

Cropanzano, R., and Greenberg, J. (1997). "Progress in organizational justice: Tunneling through the maze". In C. Cooper and I. Robertson (Eds.), International review of industrial and organizational psychology (pp. 317-372). New York: Wiley.

Demiralay, T. and Lorcu F. (2015). "Examining Organizational Silence on Doctors with Structural Equation Modeling”, International Journal of Business and Social Science, 6(9), 1: 37-49.

Fischer, R. (2004). "Rewarding employee loyalty: an organizational justice approach", International Journal of Organizational Behavior, 8:486-503.

Greenberg, J. (1987). “A Taxonomy of Organizational Justice Theories”, Academy of Management Review, 12(1): 9-22.

Greenberg, J. (1990). “Organizational Justice: Yesterday, Today, and Tomorrow”, Journal of Management, 16(2), 399-432.

Greenberg, J. (1993). "The social side of fairness: Interpersonal and informational classes of organizational justice”, In R. Cropanzano (Eds.), Justice in the workplace: Approaching fairness in human resource management (pp. 79-103). Hillsdale, NJ: Erlbaum.

Greenberg, J. and Cohen, R.L. (1982). "Equity and Justice in Social Behavior”, New York. Academic Press.

Hirschman, A. O. (1970). "Exit, Voice, and Loyalty: Responses to Decline in Firms, Organizations, and States", Cambridge, MA: Harvard University Press.

Homans, G. C. (1961). "Social Behavior: Its Elementary Forms”, New York: Harcourt, Brace and World.

Kanter, R. M. (1968). "Commitment and Social Organization: A Study of Commitment Mechanisms in Utopian Communities", American Sociological Review, 33: 499- 517.

Leventhal, G. S. (1980). "What should be done with equity theory? New approaches to the study of fairness in social relationships", In K. J. Gergen, M. S. Greenberg, and R. H. Willis (Eds.), Social exchange: Advances in theory and research (pp. 27-55). New York: Plenum.

Meyer, J. P., and Allen, N. J. (1991). "A Three-Component Conceptualization of Organizational Commitment". Human Resources Management Review, 1: 61-89.

Meyer, J. P., and Allen, N. J. (1997). “Commitment in the Workplace: Theory, Research, and Application”. London: Sage. 
Meyer P. J. and Herscovitch, L., (2001). "Commitment in the workplace toward a general model”, Human Resource Management Review, Vol. 11: 299-326.

Meyer, P.J., Stanley, J.D., Herscovitch, L., and Topolnytsky, L., (2002). "Affective, continuance, and normative commitment to the organization: A meta-analysis of antecedents, correlates, and consequences", Journal of Vocational Behavior, 61:20-52.

Milliken, F. J., Morrison, E. W., and Hewlin, P. F. (2003). "An Exploratory Study of Employee Silence: Issues that Employees Don't Communicate Upward and Why", Journal of Management Studies, 40, 1453-1476.

Morrison, E. W. (2014), "Employee Voice and Silence", The Annual Review of Organizational Psychology and Organizational Behavior, 1:173-97.

Morrison E.W. and Milliken F.J. (2000). "Organizational Silence: A Barrier to Change and Development in a Pluralistic World", The Academy of Management Review, 25(4), p.706-725.

Morrison, E. W. and Milliken, F. J. (2003), "Speaking Up, Remaining Silent: The Dynamics of Voice and Silence in organizations", Journal of Management Studies. 40(6): 1353-1358.

Mowday, R.T., Steers, R.M., and Porter, L.W. (1979). "The measurement of organizational commitment", Journal of Vocational Behavior, 14: 224-247.

Mowday, R.T., Porter, L.W. and Steers, R.M. (1982). “Employee - Organization Linkages: The Psychology of Commitment, Absenteeism, and Turnover", New York: Academic Press.

Niehoff, B. P., and Moorman, R. H. (1993). "Justice as a mediator of the relationship between methods of monitoring and organizational citizenship behavior", Academy of Management Journal, 36(3), 527-556.

Pinder, C. C., and Harlos, K. P. (2001). "Employee Silence: Quiescence and Acquiescence as Responses to Perceived Injustice", Personnel and Human Resources Management, 20, 331-369.

Salancik, G. R. (1977). "Commitment and the Control of Organizational Behavior and Belief" Pp. 1-54 in New Directions in Organizational Behavior, edited by B. M. Staw and G. R. Salancik. Chicago: St. Clair Press.

Somers, M. J. (2009). "The combined influence of affective, continuance and normative commitment on employee withdrawal", Journal of Vocational Behavior, 74:75-81.

Staw, B. M. (1977). "Two Sides of Commitment", Paper presented at the annual meeting of the Academy of Manag ement, Orlando, FL.

Steers, R. M. (1977). “Antecedents and Outcomes of Organizational Commitment”, Administrative Science Quarterly, 22:46-56.

Tangirala S. and Ramanujam R. (2008). "Employee silence on critical work issues: the cross-level effects of procedural justice climate", Personnel Psychology 61(1): 37-68.

Thibaut, J. and Walker, L. (1975). "Procedural Justice: A Psychological Analysis”, Hillsdale, N.J.: Erlbaum.

Vakola, M. and Bouradas, D. (2005). "Antecedents and Consequences of Organizational Silence: An Empirical Investigation", Employee Relations. 27(5): 441-458.

Van den Bos, K. (2001). "Fundamental Research by Means of Laboratory Experiments Is Essential for a Better Understanding of Organizational Justice", Journal of Vocational Behavior, 58, 254-259.

Van Dyne, L., Ang, S., and Botero, I. C. (2003). "Conceptualizing Employee Silence and Employee Voice as Multidimensional Constructs", Journal of Management Studies 40(6), 1359-1392.

Wasti, S. Arzu, (2002). "Affective and continuance commitment to the organization: test of an integrated model in the Turkish context", International Journal of Intercultural Relations, 26:525-550.

Wasti, S. Arzu, (2003). "The Influence of Cultural Values on Antecedents of Organizational Commitment: An Individual-Level Analysis", Applied Psychology: An International Review, Vol.52, No.4, 533-554

Wasti, S. Arzu, (2005). "Commitment profiles: Combinations of organizational commitment forms and job outcomes", Journal of Vocational Behavior, Vol.67, No.2, 290-308.

Whiteside, D. B., Barclay, L. J. (2013). "Echoes of Silence: Employee Silence as a Mediator Between Overall Justice and Employee Outcomes", Journal of Business Ethics, 116:251-266

Wiener, Y. (1982). "Commitment in Organizations: A Normative View", Academy of Management Review, 7: 418-428. 